\title{
International Human Mission to Mars: Analyzing a Conceptual Launch and Assembly Campaign
}

\author{
Grant Cates \\ Science Applications International \\ Corporation \\ 8910 Astronaut Boulevard, Suite 330 \\ Cape Canaveral, FL 32920 \\ 321-867-7820 \\ grant.r.cates@saic.com
}

\author{
Chel Stromgren \\ Binera, Inc. \\ 912 Thayer Avenue, Suite 209 \\ Silver Spring, MD 20910 \\ 301-686-8571 \\ c.stromgren@binera.com
}

\author{
Dale Arney / William Cirillo / \\ Kandyce Goodliff \\ NASA Langley Research Center \\ 1 North Dryden Street \\ Hampton, VA 23681 \\ 757-864-9297 / 757-864-1938 / 757 - \\ 864-4969 \\ dale.c.arney@nasa.gov / \\ william.m.cirillo@nasa.gov / \\ kandyce.e.goodliff@nasa.gov
}

\begin{abstract}
In July of 2013, U.S. Congressman Kennedy (DMass.) successfully offered an amendment to H.R. 2687, the National Aeronautics and Space Administration Authorization Act of 2013. "International Participation-The President should invite the United States partners in the International Space Station program and other nations, as appropriate, to participate in an international initiative under the leadership of the United States to achieve the goal of successfully conducting a crewed mission to the surface of Mars." This paper presents a concept for an international campaign to launch and assemble a crewed Mars Transfer Vehicle. NASA's "Human Exploration of Mars: Design Reference Architecture 5.0" (DRA 5.0) was used as the point of departure for this concept. DRA 5.0 assumed that the launch and assembly campaign would be conducted using NASA launch vehicles. The concept presented utilizes a mixed fleet of NASA Space Launch System (SLS), U.S. commercial and international launch vehicles to accomplish the launch and assembly campaign. This concept has the benefit of potentially reducing the campaign duration. However, the additional complexity of the campaign must also be considered. The reliability of the launch and assembly campaign utilizing SLS launches augmented with commercial and international launch vehicles is analyzed and compared using discrete event simulation.
\end{abstract}

\section{TABLE OF CONTENTS}

1. INTRODUCTION

2. COMPLEXITY AND RISKS OF LAUNCH AND

ASSEMBLY .1

3. CONCEPT OF OPERATION FOR MARS HUMAN EXPLORATION (DRA 5.0)

4. CONCEPT OF OPERATION FOR CONCEPTUAL INTERNATIONAL MISSION....................................5 5. DESCRIPTION OF SIMULATION MODEL ..........8 6. RESULTS........................................................14 7. CONCLUSIONS AND FORWARD WORK ............16 REFERENCES.................................................17 BIOGRAPHIES...................................................18

ACKNOWLEDGEMENTS....................................18

\section{INTRODUCTION}

NASA has been analyzing strategies for human exploration of Mars for many years. In 2009, NASA published "Human Exploration of Mars: Design Reference Architecture 5.0" (DRA 5.0) [1] along with a detailed technical addendum [2] that describe an operations concept for the first human missions to Mars. The Mars DRA 5.0 documents represent the most comprehensive study for human exploration of Mars published to date and now serve as the point of departure for continued studies.

There have been several key strategic changes since the 2009 timeframe that are being factored into current analyses. Changes to NASA's human exploration program since 2009 include: the cancellation of the Ares I launch vehicle; the replacement of the planned Ares V launch vehicle with the Space Launch System (SLS); and changes to the ground processing architecture. These changes have significant ramifications to the launch and assembly phase of missions to Mars.

The complex nature of Mars exploration, including launching and assembling all the required elements in a timely manner to support the planned departure window, makes reliability analysis challenging. To assist in the reliability analysis, NASA has been developing an integrated methodology to analyze launch and assembly reliability. This work builds upon previous analyses performed for the Space Shuttle and International Space Station Programs [3, 4, 5], the Constellation Program [6, 7], the Review of Human Space Flight Plans Committee [8], studies performed in 2011 on launch and assembly reliability for human exploration missions to near-Earth asteroids [9] and studies performed in 2012 on launch and assembly reliability for human exploration of Mars [10].

The integrated launch and assembly reliability methodology starts with flight hardware manufacturing and ends with final departure of a Mars Transfer Vehicle (MTV) from the Earth assembly orbit. Pertinent risk factors are accounted for within a stochastic discrete event simulation for each integrated launch and assembly campaign. 
This paper presents illustrative results from analysis of the launch and assembly campaign for the crewed nuclear thermal propulsion (NTR) MTV described in DRA 5.0 (modified to reflect NASA's programmatic changes since that time, notably the use of the SLS as opposed to the Ares V) and compares that result to launch and assembly campaigns in which commercial and international launch vehicles replace one or two of the SLS launches. Section 2 introduces the complexities and risks inherent to launch and assembly of Mars missions. Section 3 provides a brief overview of the concept of operations considered by DRA 5.0. Section 4 identifies assumptions and discusses the complexities inherent to replacing some of the SLS launches with commercial and international partner launch vehicles. Section 5 describes the discrete event simulation model used to perform the quantitative analysis. Section 6 lists the cases analyzed and presents the results. Conclusions and forward work are addressed in Section 7.

\section{COMPLEXITY AND RISKS OF LAUNCH AND ASSEMBLY}

The DRA 5.0 concept for human exploration of Mars requires multiple launches to assemble Mars Transfer Vehicles (MTVs) in Earth orbit. The process of completing all of the required launches and assembly activities will be complex and require significant time. There are several constraints that will directly impact the launch and assembly reliability. Foremost of these constraints is the limited duration of the window of opportunity for MTV departure from the Earth assembly orbit. Minimum energy departure opportunities to Mars are available from an assumed low Earth orbit (LEO) assembly orbit for an assumed period of 60 days every 26 months. The actual duration of the departure window may be different depending upon the delta velocity capacity of future MTVs and the launch opportunity. The assembly sequence will begin long before the opening of the departure window. However, if the MTV is not assembled and functional in time for the window, the window is missed and the opportunity to try again would have to wait 26 months. MTV elements stranded in Earth orbit would not likely be suitable for a Mars mission after an additional 26 month loiter. Consequently, that investment would be considered lost.

Constraints in addition to the limited departure opportunities include: the reliability of the launch vehicles, the amount of cargo up-mass and volume provided by the launch vehicles; the reliability and on-orbit lifetime capacity of the elements being placed in Earth orbit; and the ground processing architecture and workforce for preparing launch vehicles and their respective payload elements.

The United States Congress has directed NASA to develop a SLS capable of placing 130 metric tons ( $t$ ) into LEO. The mass and volumetric capacity of the $130 \mathrm{t}$ SLS enables an MTV to be assembled with as few as 4 launches. Fewer launches should be better than more launches, however reliability and launch-to-launch spacing factors need to be considered in the analysis methodology for optimizing the overall probability of launch and assembly success.

During the time that Mars DRA 5.0 was developed, NASA was planning on a robust ground processing architecture that made use of multiple launch vehicle integration high bays in the Vehicle Assembly Building (VAB) at the Kennedy Space Center along with multiple mobile launchers and two launch pads. Since that time, NASA has scaled back the plans such that only a "single-string" capacity is being put in place. This means that there will only be one mobile launcher, one launch pad and one launch vehicle integration high bay. This concept essentially precludes parallel processing of multiple launch vehicles.

In DRA 5.0, launches were planned to occur on 30-day centers. The planned single string architecture, along with planned processing on a 5 day - two 8-hour shifts per day $(5 \times 2)$, precludes this frequency of launches. SLS launch to launch spacing for a $130 \mathrm{t}$ SLS with liquid, as opposed to solid, boosters is assumed to be approximately 100 days.

Launch timeliness reliability is a significant issue since the Earth departure window is constrained. DRA 5.0 acknowledged this fact by concluding that approximately 90-180 days of margin would be inserted in the launch campaign plan between the last launch of the campaign and the opening of the Earth departure window. However, given the complexity of the launch and assembly campaign and the many delay risks, it is not clear that 90-180 days will be adequate. Unfortunately, there are also additional constraints that limit the ability to add time margin to the launch and assembly schedule.

Increasing the amount of time that elements of the MTVs loiter in the assembly orbit adds additional risk to the assembly process. The probability of system failures within the elements or of micrometeorite and orbital debris (MMOD) strikes increase as loiter time is extended. In addition, adding margin will increase the total lifetime of elements. Leaving elements in space for longer durations prior to departure could increase the risk of failure later in the mission, during more critical stages.

Crew time in space is also a major issue with adding margin to the launch and assembly process. Because the crew launch is typically the last launch in the sequence, adding margin between that event and the departure window will have the greatest benefit on reliability. However, there are significant issues to adding to the amount of time that crew must spend in space. The expected Mars mission time is approximately 2.5 years and already presents challenges to the crew. Requiring the crew to loiter at the assembly point prior to departure will only increase those risks. Additional time loitering at the assembly location also increases the risk that a crew health event will occur, requiring an abort back to Earth and thus ending the mission. 
In order to commit to a human mission to Mars, all of these constraints as well as the many risks identified below will have to be addressed such that there is an acceptably high level of confidence that the launch and assembly will be successful.

\section{Types of Risks}

The types of risks involved in the launch and assembly of the MTVs can be divided into two major categories: PreLaunch Risks and Post-Launch Risks. Pre-Launch Risks are those that occur prior to ignition of the main engines of the launch vehicle for any launch that supports the mission. These risks involve all of the activities required to manufacture, deliver, assemble, and prepare each vehicle for launch. Post-Launch Risks are those that occur after the ignition of the main engines of the launch vehicle and involve all of the activities required to position and assemble elements, deliver the crew to the MTVs, and prepare for departure. They are discussed in further detail in Section 4.

The constraints and risks described herein require that missions be designed in a way that the total achieved launch and assembly reliability will result in an acceptable probability of mission success. The reliability and the timing of launch and assembly events must be carefully evaluated in order to identify and mitigate those risks.

There is a fundamental tension between adding margin to the launch schedule and the amount of in-space risk exposure. A balance must be achieved between these factors in order to develop an acceptable level of overall reliability.

This evaluation should occur in conjunction with the analysis and design of the launch systems and MTV elements. Because most of these systems and many of the technologies that are incorporated into them do not yet exist, it is still possible to influence capabilities and system reliabilities in order to achieve a reasonable overall reliability.

\section{CONCEPT OF OPERATION FOR MARS HUMAN EXPLORATION (DRA 5.0)}

The basic concept of operations described in Mars DRA 5.0 was to send three Mars Transfer Vehicles (MTVs) to Mars as shown in Figure 1 [1]. Each of the three MTVs would propel one of the three major payload elements required at Mars to conduct the mission. These were: (1) a Mars surface habitat (the SHAB) that the crew uses to descend to the Mars surface and where they live in and work from during their stay on Mars; (2) a Mars descent / ascent vehicle (the MDAV) that is used to descend exploration gear to the Mars surface and then at the conclusion of the Mars surface mission to ascend the crew back to Mars orbit; and (3) the deep space transit habitat (the HAB) that the crew would live in during their transit from Earth orbit to Mars orbit and back. Figure 2 [1] provides additional detail on the Crewed MTV.

Mars DRA 5.0 considered two propulsion concepts for the MTVs, Nuclear Thermal Rocket (NTR) or Chemical. For the purposes of this paper, only the NTR case is considered. In the example depicted in Figure 1 the SHAB and MDAV were "pre-deployed" in that they were sent to Mars 26 months prior to departure of the crew from Earth orbit. The analysis presented in this paper is limited to the launch and assembly campaign for the crewed MTV.

DRA 5.0 describes the crewed MTV as follows. "The 'allpropulsive' crewed MTV has an IMLEO of $356.4 \mathrm{t}$ and an overall vehicle length of $96.7 \mathrm{~m}$. It is an 'in-line' configuration, which, like the cargo MTV, uses AR\&D to simplify vehicle assembly. It uses the same common NTR propulsion stage but includes additional external radiation shielding on each engine for crew protection during engine operation. It also includes two saddle trusses that are open on the underside for jettisoning of the drained [liquid hydrogen] LH2 drop tank and unused contingency consumables at the appropriate points in the mission. Four $12.4 \mathrm{kWe} / 125 \mathrm{~m}^{2}$ rectangular photovoltaic arrays which are attached to the front end of the short saddle truss, provide the crewed MTV with $50 \mathrm{kWe}$ of electrical power for crew life support, propellant tank ZBO cryocoolers and highdata-rate communications with Earth." [1]

DRA 5.0 planned for four Ares V launches over 90 days to deliver the crew MTV vehicle components to a 407-km circular assembly and departure orbit. The four launches were:

1 NTR “core" propulsion stage (106.2 t)

2 In-line propellant tank $(91.4 \mathrm{t})$

3 Saddle truss and LH2 drop tank (96 t)

4 Supporting payload (62.8 t)

The supporting payload launch includes: the transit habitat; the long-lived Orion/service module; a short saddle truss for connecting the habitat to the rest of the MTV; a T-shaped docking module (DM) that connects the contingency consumables container with the habitat's rear hatch and also provides a docking port for delivery of the crew. Mass details for the crewed MTV are shown in Table 1.

The launch order of the crewed MTV elements would begin with the Payload Elements, followed by the Long Saddle Truss \& LH2 Drop Tank, the In-Line LH2 Tank, and then the NTR Core Stage. The crew would be launched last and as close to the opening of the trans-Mars-injection (TMI) as possible while maintaining a sufficient buffer to account for launch delay risk. 


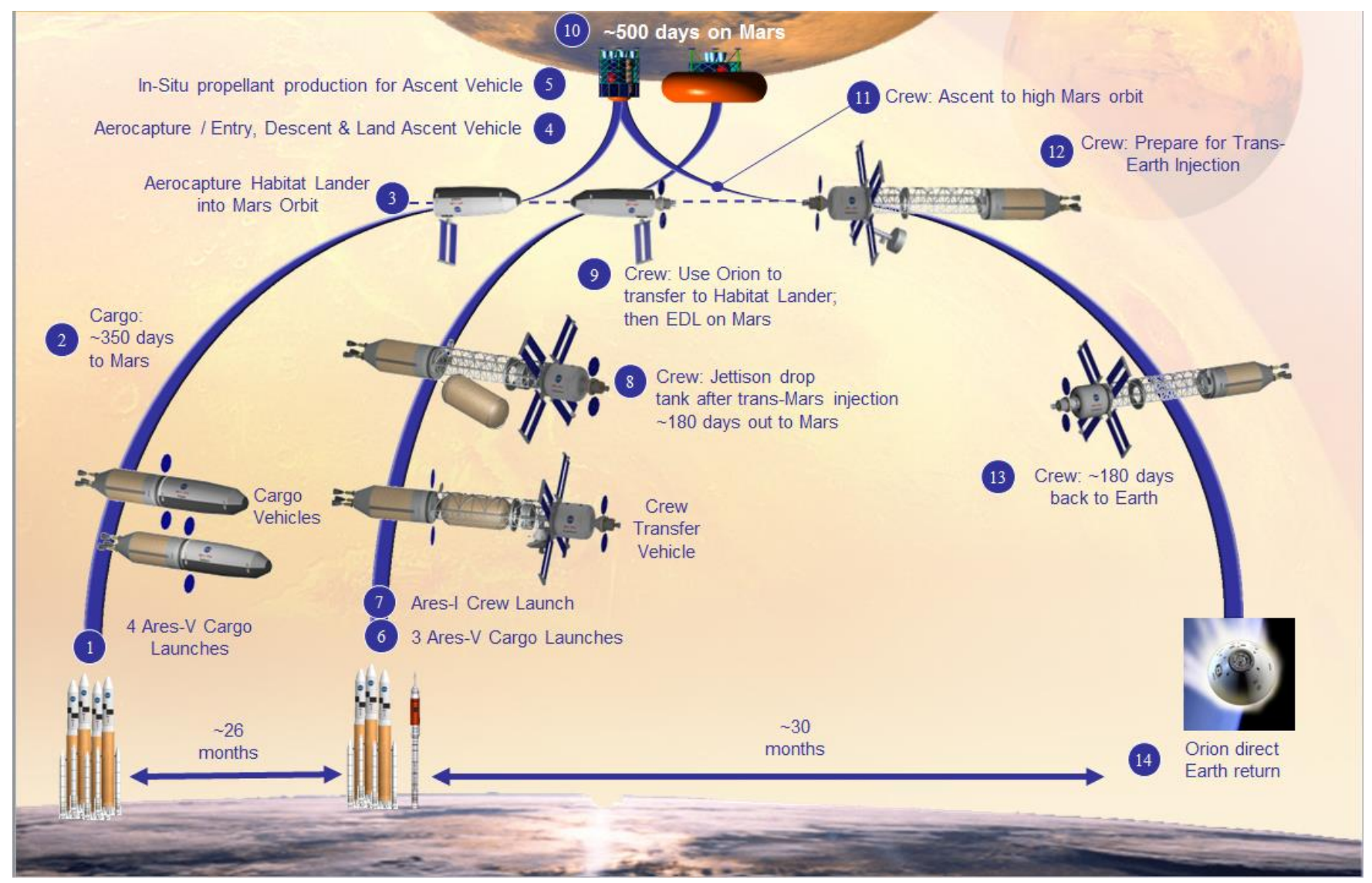

Figure 1 - Example Concept of Operations from Mars DRA 5.0 - “Pre-deployed" \& NTR [1]

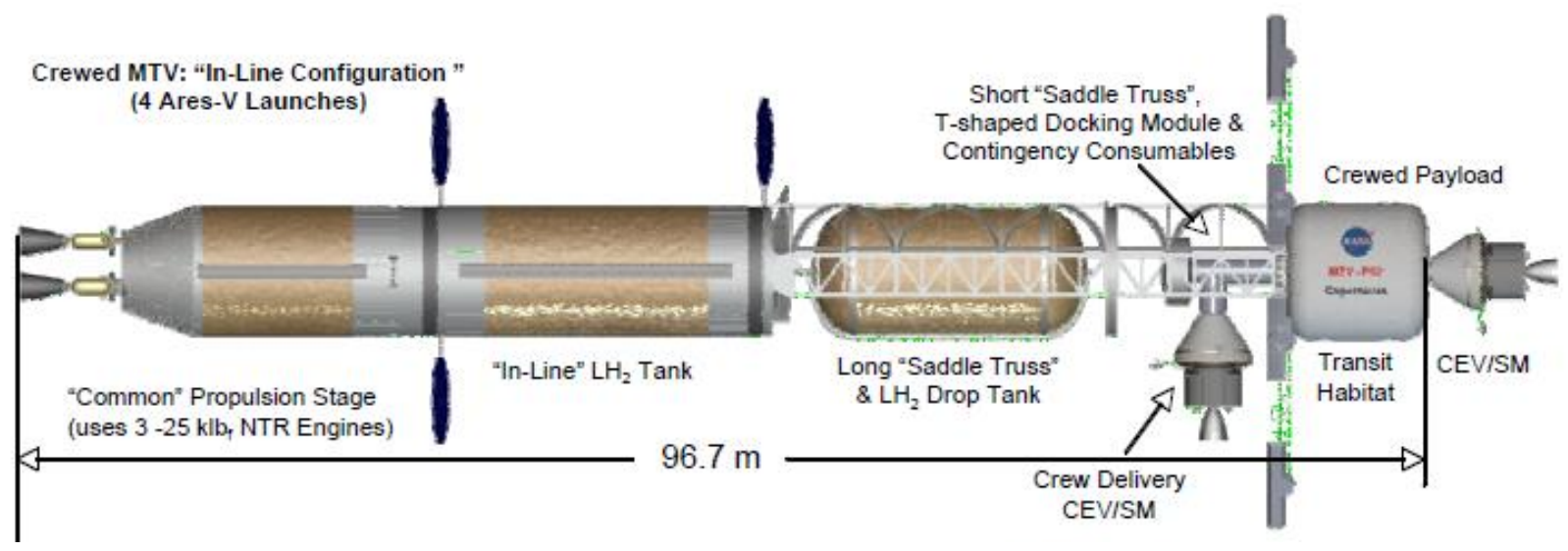

Figure 2 - Crewed Mars Transfer Vehicle Configuration [1] 
Table 1. Crewed MTV Mass Details [1]

\begin{tabular}{|l|l|c|}
\hline Vehicle Elements & Mass (t) \\
\hline NTR Core Stage & Core Stage Dry Mass & 41.7 \\
& LH2 Propellant Load & 59.7 \\
& RCS Propellant Load & 4.9 \\
& Total Core Stage Mass & $\mathbf{1 0 6 . 2}$ \\
\hline In-Line LH2 Tank & In-Line Dry Mass & 21.5 \\
& LH2 Propellant Load & 69.9 \\
& Total In-Line Mass & $\mathbf{9 1 . 4}$ \\
\hline Long Saddle Truss \& & Saddle Truss Mass & 8.9 \\
LH2 Drop Tank & Drop Tank Dry Mass & 14.0 \\
& LH2 Propellant Load & 73.1 \\
& Total Assembly Mass & $\mathbf{9 6 . 0}$ \\
\hline Payload Elements & Short Saddle Truss & 4.7 \\
& Contingency Food Canister & 9.8 \\
& 2 ${ }^{\text {nd }}$ Docking Module & 1.8 \\
& FWD RCS Prop Load & 3.2 \\
& Transit Habitat & 32.8 \\
& Long-Lived Orion/SM & 10.6 \\
& Total Payload Mass & $\mathbf{6 2 . 8}$ \\
\hline \multicolumn{2}{|l}{ Total Crewed Vehicle Mass } & $\mathbf{3 5 6 . 4}$ \\
\hline
\end{tabular}

Subsequent to DRA 5.0 publication, development of the Ares V and Ares I launch vehicles was terminated. However, the $130 \mathrm{t}$ SLS will have similar capabilities so it is assumed that the crewed MTV could be assembled with four launches of the $130 \mathrm{t}$ capable SLS. NASA is providing funding to multiple commercial ventures to assist in developing crew transportation capabilities to LEO. It is assumed that at least one of these ventures will be capable of transporting the Mars crew to the MTV assembly orbit.

\section{CONCEPT OF OPERATION FOR CONCEPTUAL INTERNATIONAL MISSION}

The team modified the concept of operations for DRA 5.0 to include commercial and international launch service providers. The first step is to determine the capabilities of the various government, commercial and international launch service providers. It is assumed that the parameters of the assembly orbit are an altitude of $400 \mathrm{~km}$ and an inclination of 28.5 degrees. The inclination assumption may need to be revised in the future depending upon what international partner launch service providers are included in the campaign. The two metrics of interest are mass and payload volume that a launch vehicle can place in the assembly orbit, with volume being the limiting factor in most of the launches. The estimated values are shown in Table 2 along with the payload fairing diameters. Most of these values came from the payload planners guides for the launch vehicles. The mass values may need to be revised depending upon the assembly parameter values ultimately chosen.

The Falcon Heavy is currently advertised on the Space Explorations Technology website with a payload fairing identical in size (5.1m diameter, $13.1 \mathrm{~m}$ height) to the Falcon 9 [11]. For the purposes of this paper, it was assumed that a stretched fairing would be available, similar in volume capacity to the Delta IV Heavy.
Table 2. Launch Vehicle Capability Metrics

\begin{tabular}{|l|c|c|c|c|}
\hline Launch Vehicle & $\begin{array}{c}\text { Mass } \\
\text { to } \\
\text { LEO } \\
(\mathrm{t})\end{array}$ & $\begin{array}{c}\text { Payload } \\
\text { Volume } \\
\left(\mathrm{m}^{3}\right)\end{array}$ & $\begin{array}{c}\text { Fairing } \\
\text { Diameter } \\
(\mathrm{m})\end{array}$ & $\begin{array}{c}\text { SLS } \\
\text { Volume } \\
\text { Ratio }\end{array}$ \\
\hline SLS & 130 & 2,026 & 10 & 1 \\
\hline $\begin{array}{l}\text { Falcon Heavy } \\
\text { (with stretched } \\
\text { fairing) }\end{array}$ & 53 & 224 & 5 & $1 / 9$ \\
\hline $\begin{array}{l}\text { Falcon Heavy } \\
\text { (with current } \\
\text { fairing) }\end{array}$ & 53 & 156 & 5 & $1 / 13$ \\
\hline Delta IV H & 23 & 221 & 5 & $1 / 9$ \\
\hline Ariane V & 20 & 209 & 5 & $1 / 10$ \\
\hline Atlas V (551) & 18 & 233 & 5 & $1 / 9$ \\
\hline Falcon 9 1.1 & 16 & 156 & 5 & $1 / 13$ \\
\hline H-IIB & 16 & 146 & 5 & $1 / 14$ \\
\hline Delta IV M & 13 & 146 & 5 & $1 / 14$ \\
\hline Soyuz & 9 & 85 & 4 & $1 / 24$ \\
\hline Antares & 5 & 85 & 3.9 & $1 / 24$ \\
\hline
\end{tabular}

The volume differential between the SLS and all the other launch vehicles is quite significant. It will take multiple launches, as many as 9 to 24 depending upon the vehicles being used, to volumetrically replace a single Block $2130 \mathrm{t}$ SLS launch. This fact coupled with the fairing diameter reduction means that the concept of operations for the conceptual International human mission to Mars will need to be considerably different than the one described in DRA 5.0.

This paper will first describe a concept in which there are 3 SLS launches as opposed to 4 . The primary consideration is which of the three MTV elements shown in Table 1 and Figure 2 should be launched using the SLS launch vehicles, and which one should be fractionated so as to launch on multiple non-SLS launch vehicles. The three propulsion elements are dominated by large LH2 tanks. LH2 has a very low density of 0.071 tons per cubic meter. With a combined LH2 requirement of 390 tons, the volumetric requirement for the LH2 alone is 5,500 cubic meters. Consequently, focusing the three SLS launches on the propulsion elements is warranted. Additionally, in looking at the payload elements shown in Figure 2 and their respective masses in Table 1, a logical way to fractionate the payload elements can be devised.

Table 3 shows the alternate launch vehicles that could be used to launch the fractionated sub elements of the payload elements. The mass values in Table 3 are taken from Table 1. Additional mass will likely be required to account for the rendezvous, docking and assembly activities to integrate the fractionated sub elements on orbit. Table 3 shows that there is mass margin available to account for that additional overhead. However, while the mass constraints are satisfied by the alternate launch vehicles, the volumetric analysis is only notional at this point. It is also assumed that the HAB could be modified to be an inflatable design in order to be accommodated by a launch vehicle with a 5 meter diameter fairing. For this case, further analysis would need to be 
completed to determine if there was enough volume for the consumables needs for the Mars mission. An additional launch might need to be added to account for all the consumables. Likewise, the actual inflation and assembly of the MTV might require an on-orbit assembly crew and that would mean more launches would be required.

Table 3. MTV Payload Elements Fractionation

\begin{tabular}{|c|c|c|c|}
\hline $\begin{array}{l}\text { MTV Payload } \\
\text { Elements }\end{array}$ & $\begin{array}{c}\text { Mass } \\
\text { (t) }\end{array}$ & $\begin{array}{c}\text { Alternate } \\
\text { Launcher }(\& \text { Mass } \\
\text { Capacity }(\mathrm{t}))\end{array}$ & $\begin{array}{l}\text { Mass } \\
\text { Margin } \\
(\mathrm{t})\end{array}$ \\
\hline Short Saddle Truss & 4.7 & Atlas V (18) & 13.3 \\
\hline $\begin{array}{l}\text { Four } 12.4 \mathrm{kWe}- \\
125 \mathrm{~m}^{2} \text { PVAs }\end{array}$ & $*$ & \multirow[t]{2}{*}{ Soyuz (9) } & \multirow[t]{2}{*}{9} \\
\hline $\begin{array}{l}\text { Zero-Boiloff Cryo } \\
\text { Coolers }\end{array}$ & $*$ & & \\
\hline $\begin{array}{l}\text { Contingency Food } \\
\text { Canister }\end{array}$ & 9.8 & Ariane V (20) & 10.2 \\
\hline $2^{\text {nd }}$ Docking Module & 1.8 & \multirow{2}{*}{ HII-B (16) } & \multirow{2}{*}{11} \\
\hline FWD RCS Prop Load & 3.2 & & \\
\hline Transit Habitat (HAB) & 32.8 & Falcon Heavy (53) & 20.2 \\
\hline $\begin{array}{l}\text { Long-Lived Orion and } \\
\text { SM }\end{array}$ & 10.6 & $\begin{array}{lll}\begin{array}{l}\text { Delta IV Heavy } \\
(23)\end{array} & \\
\end{array}$ & 12.4 \\
\hline Total Payload Mass & 62.8 & & \\
\hline
\end{tabular}

* Mass for PVAs and Cryo Coolers is not shown in

DRA 5.0; if these are not included in the mass breakdown, the authors left a launch available for these items

The launch order would begin with the Atlas V followed by the Soyuz. Once their respective sub-elements-Short Saddle Truss, Solar Power System, and the all-important Zero-Boiloff Cryo Coolers-are connected, then assembly of the remainder of the MTV including the LH2 based elements and the HAB can proceed.

The second concept considered in this paper is one in which there are only 2 SLS launches. In addition to the MTV Payload Elements launched by non-SLS launches, one of the 3 LH2 based elements must be identified to fractionate. The Long Saddle Truss / LH2 Drop Tank was chosen because it is already fractionated to some degree. Also the concept of a truss with multiple tanks rather than one large tank lends itself to using non-SLS launch vehicles that have a 5-meter fairing diameter. Consequently, it is assumed that the optimal use of the 2 SLS launches is to place the NTR Core Stage and In-Line LH2 Tank in low Earth orbit.

Given the case in which there are only 2 SLS launches available, the MTV configuration shown in Figure 2 is still supportable given some key distinctions. First, as previously mentioned, the HAB will need to be an inflatable. Second, the one large drop tank must be sub-divided. At least 4 , and potentially more, LH2 drop tanks will be required. Approximately 4 5-meter class diameter tanks would be required to replace 110 -meter class diameter tank of approximately equal lengths. The saddle truss shown in the figure would more likely end up being a center-line pentagon shaped truss with attach stations for the $4 \mathrm{LH} 2$ tanks. The truss would support a movable robotic arm that would be used to capture the LH2 tanks and berth them to their respective attach stations.

Figure 3 shows a simple cross section of 4 LH2 drop tanks attached to a center-line pentagon shaped truss along with a stowed robotic arm. The cross sectional dimension of the centerline truss would be such that it would fit within a 5-m diameter payload fairing.

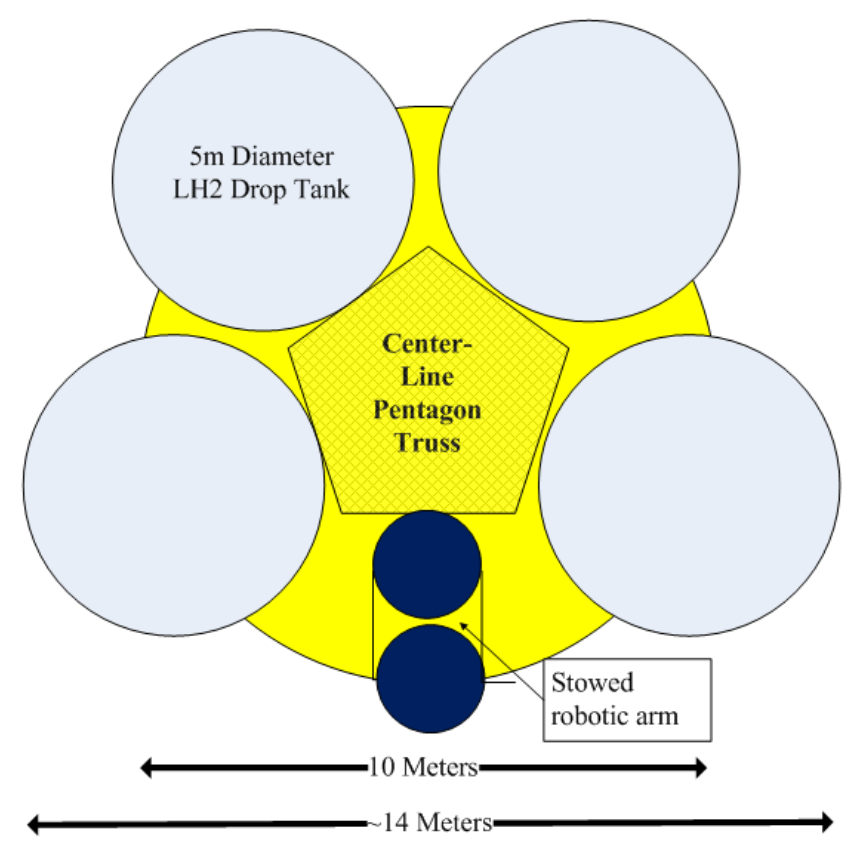

Figure 3 - Cross Section Detail

Cases with fewer than 2 SLS launches were not analyzed for this paper. However, the strategy for their analysis would be similar. A 1-SLS case would be similar to the 2-SLS case with the addition of needing to fractionate the in-line hydrogen tank. That would be done in similar fashion to how the LH2 drop tank was fractionated as shown in Figure 3. A case with no SLS launches would mean that the NTR propulsion module would need to be fractionated. Each of the 3 NTR engines would need to be launched separately. Another launch would be required to place the thrust structure and main propulsion plumbing system. On-orbit integration of the engines with the thrust structure, fluid lines and electrical lines would be required. The hydrogen propellant tank would also need to be fractionated and launched on multiple vehicles.

Table 4 provides launch campaign planning information for the four scenarios that were analyzed (the baseline DRA 5.0, the modified baseline case, and the two mixed launch vehicle concepts). The left column provides the number of days relative to the opening of the TMI window. For DRA 5.0, the first Ares V launch would have been planned for 270 days prior to the TMI window opening. Three additional Ares V launches would have followed on 30-day centers. A buffer of 150 days protects for Ares V launch delays. The Ares I crew launch was planned for 30-days prior to the TMI window opening. The new analysis point 
of departure is based upon SLS launch vehicles with approximately 105-day spacing between launches including a spare launch opportunity followed by additional margin of 105 days prior to a commercial provider launching the crew.
The 3-SLS and 2-SLS options maintain the same SLS launch to launch spacing and spare opportunity, while adding cargo launches from commercial and international launch service providers.

Table 4. Launch Campaign Plans

\begin{tabular}{|c|c|c|c|c|}
\hline $\begin{array}{l}\text { Days Relative } \\
\text { to Opening of } \\
\text { TMI Window }\end{array}$ & DRA 5.0 & $\begin{array}{c}\text { New Analysis Point of } \\
\text { Departure }\end{array}$ & 3-SLS Option & 2-SLS Option \\
\hline 60 & \multicolumn{4}{|c|}{ TMI Injection Window Closes } \\
\hline \multicolumn{5}{|l|}{45} \\
\hline \multicolumn{5}{|l|}{30} \\
\hline \multicolumn{5}{|l|}{15} \\
\hline 0 & \multicolumn{4}{|c|}{ TMI Injection Window Opens } \\
\hline-15 & 30-day crew launch buffer & 30-day crew launch buffer & 30-day crew launch buffer & 30-day crew launch buffer \\
\hline-30 & Ares I: Crew & Commercial Crew & Commercial Crew & Commercial Crew \\
\hline-45 & \multirow{9}{*}{$\begin{array}{c}150 \text { days of } \\
\text { MTV } \\
\text { launch \& assembly } \\
\text { campaign } \\
\text { buffer }\end{array}$} & \multirow{7}{*}{$\begin{array}{c}\sim 120 \text { days of } \\
\text { MTV } \\
\text { launch \& as sembly } \\
\text { campaign buffer }\end{array}$} & & \\
\hline-60 & & & Atlas V: Spare (as-needed) & Atlas V: Spare (as-needed) \\
\hline-75 & & & Delta IV H: Spare (as-needed) & Delta IV H: Spare (as-needed) \\
\hline-90 & & & Ariane V: Spare (as-needed) & Ariane V: Spare (as-needed) \\
\hline-105 & & & Falcon H: Spare (as-needed) & Falcon H: Spare (as-needed) \\
\hline-120 & & & H2B: Spare (as-needed) & H2B: Spare (as-needed) \\
\hline-135 & & & Soyuz: Spare (as-needed) & Soyuz: Spare (as-needed) \\
\hline-150 & & SLS: Spare (as-needed) & SLS: Spare (as-needed) & SLS: Spare (as-needed) \\
\hline-165 & & \multirow{6}{*}{$\begin{array}{c}\sim 105-\text { Day } \\
\text { Launch-to-Launch } \\
\text { Turnaround }\end{array}$} & & \\
\hline-180 & Ares V: NTR Prop Module & & & \\
\hline-195 & & & & \\
\hline-210 & Ares V: In-Line Tank & & Delta IV H: Orion \& SM & Delta IV H: Orion \& SM \\
\hline-225 & & & Ariane V: Contingency Food & Ariane V: Contingency Food \\
\hline-240 & $\begin{array}{l}\text { Ares V: Saddle Truss / } \\
\text { Drop Tank }\end{array}$ & & $\begin{array}{l}\text { Falcon H: Inflatable Trans- } \\
\mathrm{Hab}\end{array}$ & $\begin{array}{l}\text { Falcon H: Inflatable Trans- } \\
\mathrm{Hab}\end{array}$ \\
\hline-255 & & SLS: NTR Prop Module & SLS: NTR Prop Module & SLS: NTR Prop Module \\
\hline-270 & Ares V: Payload Elements & \multirow{6}{*}{$\begin{array}{c}\sim 105-\text { Day SLS } \\
\text { Launch-to-Launch } \\
\text { Turnaround }\end{array}$} & \multirow{6}{*}{$\begin{array}{c}\sim 105-\text { Day SLS } \\
\text { Launch-to-Launch } \\
\text { Turnaround }\end{array}$} & \\
\hline-285 & & & & \\
\hline-300 & & & & Atlas V: H2 Tank \\
\hline-315 & & & & Delta IV H: H2 Tank \\
\hline-330 & & & & Ariane V: H2 Tank \\
\hline-345 & & & & Falcon H: H2 Tank \\
\hline-360 & & SLS: In-Line Tank & SLS: In-Line Tank & SLS: In-Line Tank \\
\hline-375 & & \multirow{6}{*}{$\begin{array}{c}\text { 105-Day SLS } \\
\text { Launch-to-Launch } \\
\text { Turnaround }\end{array}$} & \multirow{6}{*}{$\begin{array}{c}\sim 105-\text { Day SLS } \\
\text { Launch-to-Launch } \\
\text { Turnaround }\end{array}$} & \\
\hline-390 & & & & \\
\hline-405 & & & & Falcon H: Saddle Truss \\
\hline-420 & & & & $\begin{array}{l}\text { Soyuz: Power System \& ZBO } \\
\text { Cryo-Coolers }\end{array}$ \\
\hline-435 & & & & $\begin{array}{l}\text { H2B: 2nd Docking Module; } \\
\text { Fwd RCS Prop }\end{array}$ \\
\hline-450 & & & & Atlas V: Short Saddle Truss \\
\hline-465 & & $\begin{array}{l}\text { SLS: Saddle Truss / Drop } \\
\text { Tank }\end{array}$ & $\begin{array}{l}\text { SLS: Saddle Truss / Drop } \\
\text { Tank }\end{array}$ & \\
\hline-480 & & \multirow{6}{*}{$\begin{array}{c}\sim 105-\text { Day } \\
\text { Launch-to-Launch } \\
\text { Turnaround }\end{array}$} & & \\
\hline-495 & & & & \\
\hline-510 & & & $\begin{array}{l}\text { Soyuz: Power System \& ZBO } \\
\text { Cryo-Coolers }\end{array}$ & \\
\hline-525 & & & $\begin{array}{l}\text { H2B: 2nd Docking Module; } \\
\text { Fwd RCS Prop }\end{array}$ & \\
\hline-540 & & & Atlas V: Short Saddle Truss & \\
\hline-555 & & & & \\
\hline-570 & & SLS: Payload Elements & & \\
\hline
\end{tabular}


The new analysis point of departure recognizes the change from Ares V to SLS and the change from Ares I for crew to commercial crew. Additionally, previous analysis has demonstrated that having a spare launch vehicle and spare MTV elements is critical to achieving high launch and assembly campaign reliability [10]. For this analysis cycle it was assumed that 1 spare SLS launch is planned on an asneeded basis. Likewise, the 3-SLS and 2-SLS options assume that each commercial and international partner will provide 1 spare launch vehicle on an as-needed basis with a 30-day call-up. A 30-day call-up capability means that if a launch vehicle experiences a failure, then a spare launch vehicle can be launched as soon as 30 days later. This also implies that there is a ready spare for the lost payload element.

\section{DESCRIPTION OF Simulation MODEL}

A stochastic discrete event simulation model was created using Rockwell Automation's Arena simulation software [12]. Figure 4 provides a high level overview of the model, which includes linkages to Excel files for inputs and results. The model logic includes entity routing to reflect all of the major processes and operations in the launch and assembly sequence from manufacturing completion through readiness and performance of the Earth departure burn, as shown in Figure 5.

The simulation is run for 1,000 replications, with each replication representing one possible manifestation of the launch and assembly sequence. The only difference between the replications is the random numbers used to drive the various risk models.

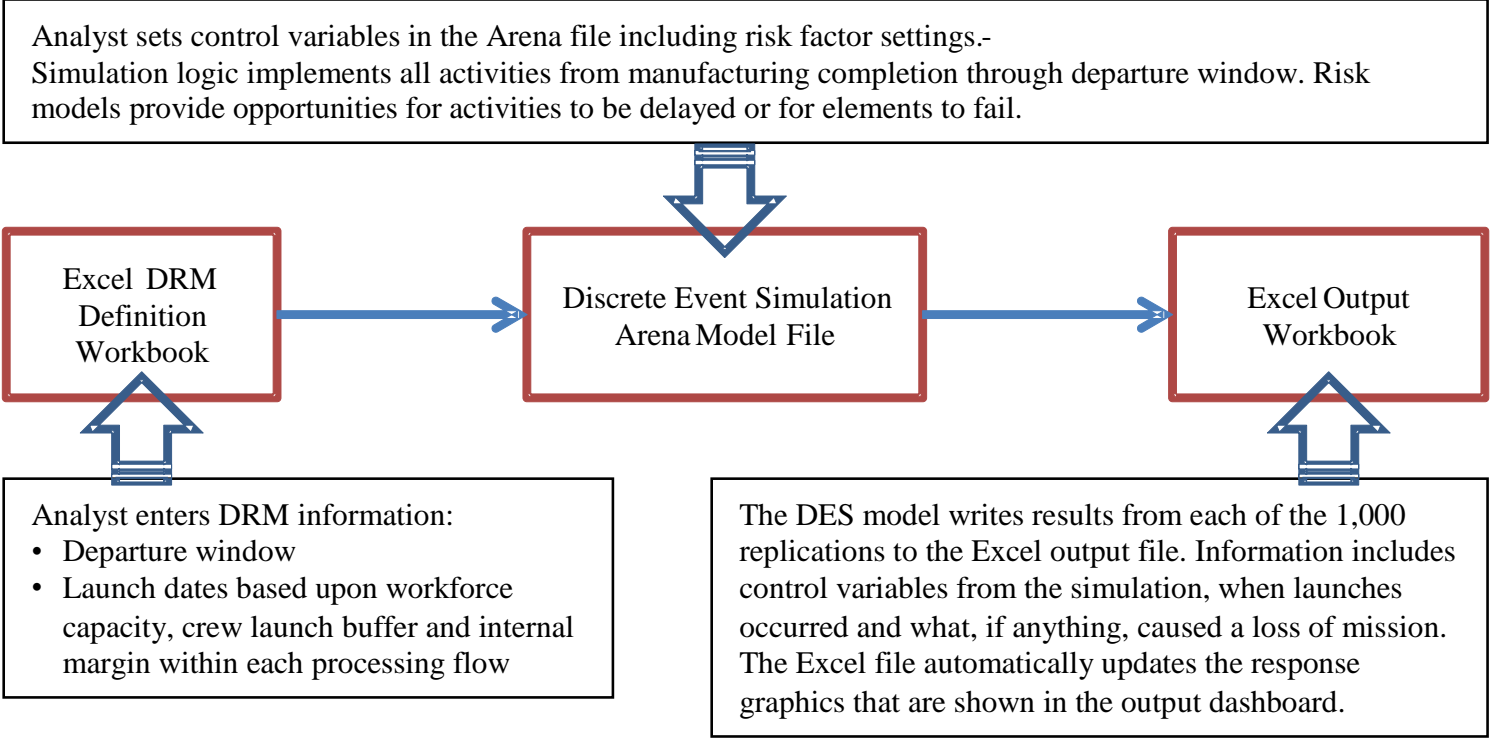

Figure 4 - Model Overview 


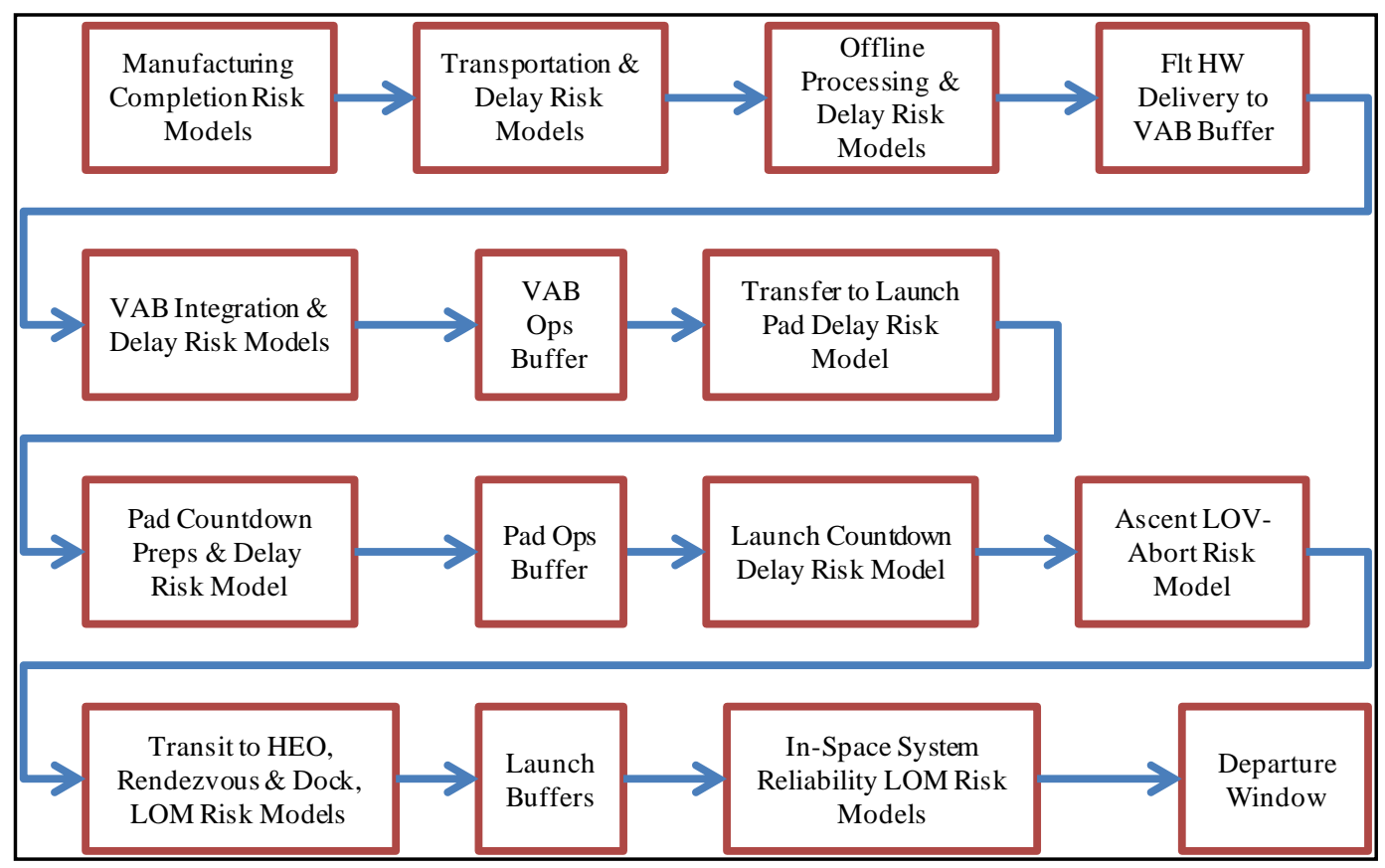

Figure 5 - Flight Hardware Elements Entity Routing Within Model

\section{Overview of Risk Models}

Manufacturing, Processing \& Launch Campaign Risks-All elements for the Mars mission, including MTVs elements, launch vehicles, and propulsive elements must be manufactured, tested, and delivered to their respective space centers. Delays in these activities would delay the launch and assembly schedule.

The risk of SLS manufacturing related delays was quantified using Space Shuttle historical data. Processing capabilities for the SLS at the Kennedy Space Center are limited by facilities and personnel constraints. These constraints dictate the planned launch schedule for elements. Delays in completing element processing and launch vehicle assembly could significantly impact the launch and assembly schedule. Delay risks through the start of launch countdown for the SLS launch vehicle have been previously described in detail [9] and were used again for this analysis.

Non-SLS launch vehicles historical information from SpaceflightNow.com's launch schedule and launch log was initially analyzed. Their launch schedule has about a 6 month to one-year horizon, meaning that when a planned launch date is set on their schedule, the planned launch is 6 to 12 months away. The launch schedule is updated with any changes to the launch date. Once the launch has actually occurred, the history of delays is documented in their launch $\log$. The team analyzed the initial planned launch date versus the actual launch date to create cumulative launch delay distribution functions for each of the commercial and international partner launch service providers. The results are shown in Figure 6. 


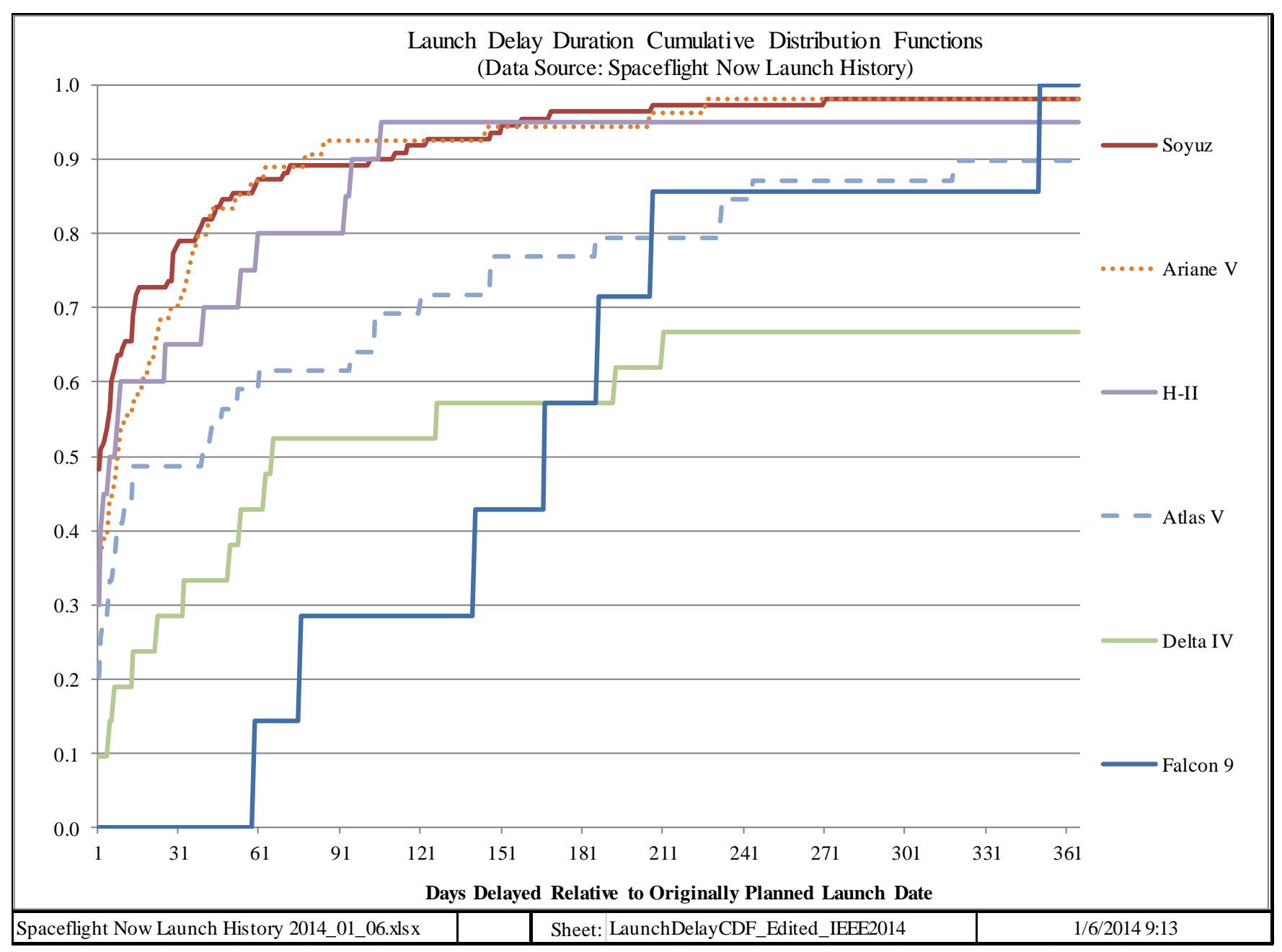

\section{Figure 6 - Launch Delays Relative to When a Launch First Comes Onto the SpaceflightNow.com Launch Schedule (approximately one year out)}

The probability of launching on the originally planned date varies from approximately 50 percent for Soyuz to 0 percent for Falcon 9. Note that Falcon 9 has been launched 7 times thus far through December of 2013. Of more interest is how much margin is required to get to a high cumulative probability of launch. Suppose a $90 \%$ confidence of launch occurring within a specified time was desired. For Soyuz, $\mathrm{H}-\mathrm{II}$ and Ariane V, the $90^{\text {th }}$ percentile is achieved within 100 days or so. For the Atlas V and Falcon 9 the $90^{\text {th }}$ percentile is occurring nearly a year out from the planned launch date. The Delta IV does not achieve the $90^{\text {th }}$ percentile within a year. These results do not bode well for supporting a time constrained MTV assembly campaign. However, the authors believe that cumulative launch probability can be enhanced.

First it is important to keep in mind that at the time a mission enters the SpaceFlightNow.Com launch schedule the spacecraft and launch vehicle may still be in manufacturing and have typically not been shipped to the launch site.
Secondly, no one has ever used multiple launch vehicles to assemble a spacecraft in orbit that was intended to travel beyond Earth orbit. All spacecraft that have left Earth orbit have been launched on a single launch vehicle. There have been many planetary missions flown to date and most were able to launch without significant delay relative to their planned launch date once they got within a year of launch and were still on schedule. One reason for this launch timeliness success may be extraordinary measures that are taken to ensure that the departure window is not missed. These measures include: not committing to the mission until both the launch vehicle and spacecraft are go to begin processing; adding significant margin to the processing schedule; and in the case of the Space Shuttle, even designating a backup orbiter until it becomes clear that the primary orbiter is going to be available.

Consequently, it is assumed that the first launch in the sequence will not be attempted if there are significant threats to any of the subsequent launchers and their respective payloads. In other words, all of the launch vehicles and payloads are manufactured, tested and at their respective launch sites in ready storage. Additionally it is 
assumed that substantial margin is added to the launch site processing schedules such that it can be assumed that most, if not all, pre-launch countdown delay risk is mitigated.

The next step is to determine the appropriate launch countdown delay risk model to use for the SLS and nonSLS launch vehicles.

The SLS launch countdown delay risk model used for this analysis is based primarily upon Space Shuttle (a.k.a. STS) historical data coupled with the expected differences between the Space Shuttle and SLS. Figure 7 shows the actual cumulative distribution function (CDF) created from the launch countdown history of 135 Space Shuttle missions along with the projected launch countdown delay distribution functions for the $105 \mathrm{t}$ SLS (both crew and cargo variants) and the $130 \mathrm{t}$ cargo SLS.

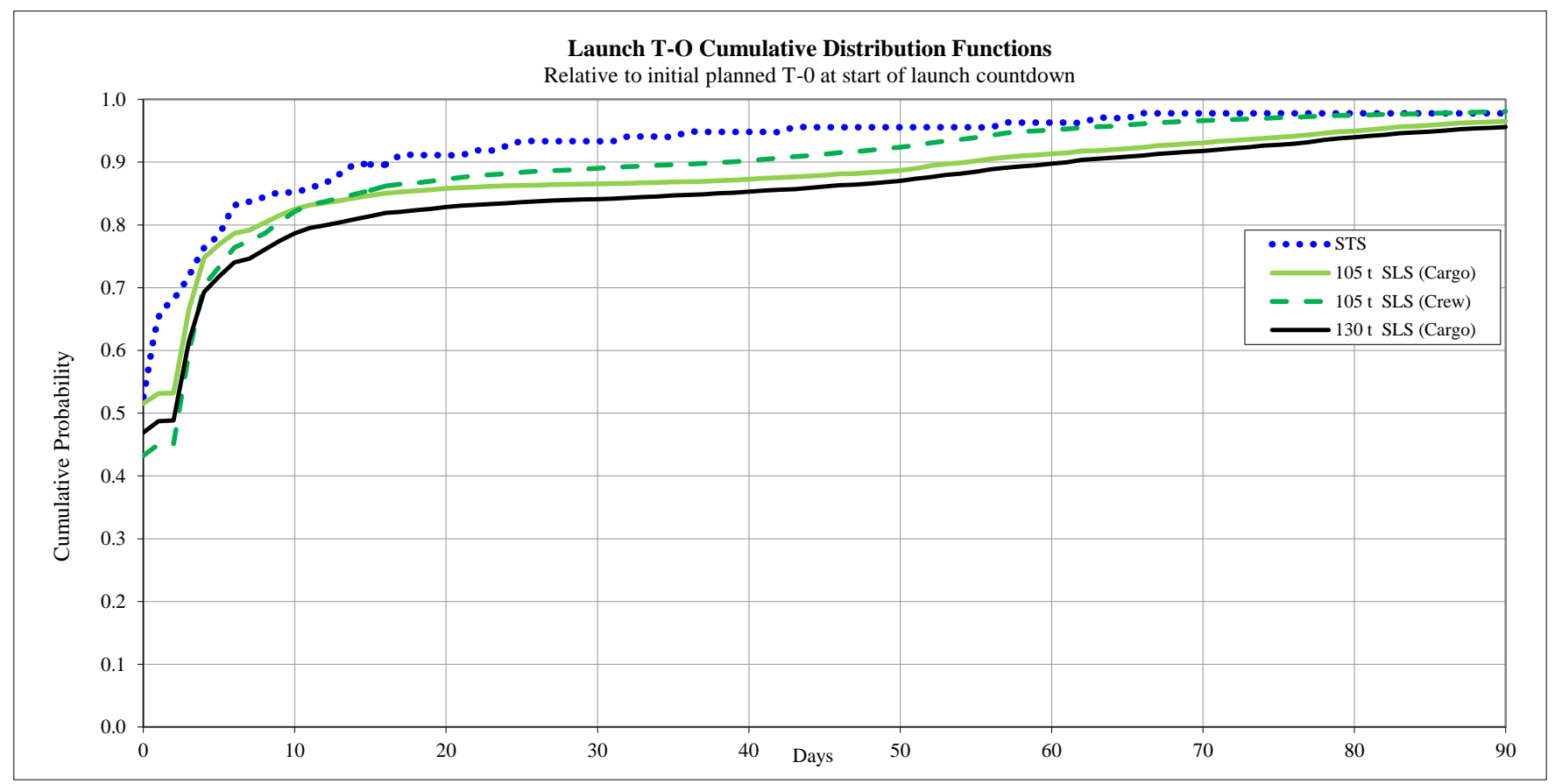

Figure 7 - SLS Launch Countdown Delay Risk Models

The projected distributions lie below the STS distribution for a number of reasons, including: 4 versus 3 Space Shuttle Main Engine (SSME) class engines; the ground architecture's limited capacity, relative to the capacity during the STS program, to perform consecutive propellant loadings of the SLS; the ground architecture's clean pad concept which limits the ability to perform troubleshooting at the launch pad and increases the likelihood of needing to roll-back to the VAB in the event of a technical scrub; and in the case of crewed launches, the need to consider the sea state conditions in the Orion ocean abort zones.

These projections are subject to a fair amount of uncertainty today, and to change in the future, given that the SLS and payloads to be flown have not yet been developed, let alone established a launch history. For the time being they are believed to represent a reasonable estimate.

For the non-SLS launch vehicles, the team encountered some difficulty with consistently identifying the date of the first launch attempt in the SpaceFlightNow.com data base. Consequently, the team analyzed the history of Atlas V and Delta IV launches for which there are multiple sources describing when the initial launch attempts were made. The team combined the data from both launch vehicles to create a composite launch countdown delay CDF as shown in Figure 8. This CDF is used for all non-SLS launch vehicles. It is noteworthy that this CDF is better relative to the $130 \mathrm{t}$ SLS CDF. 


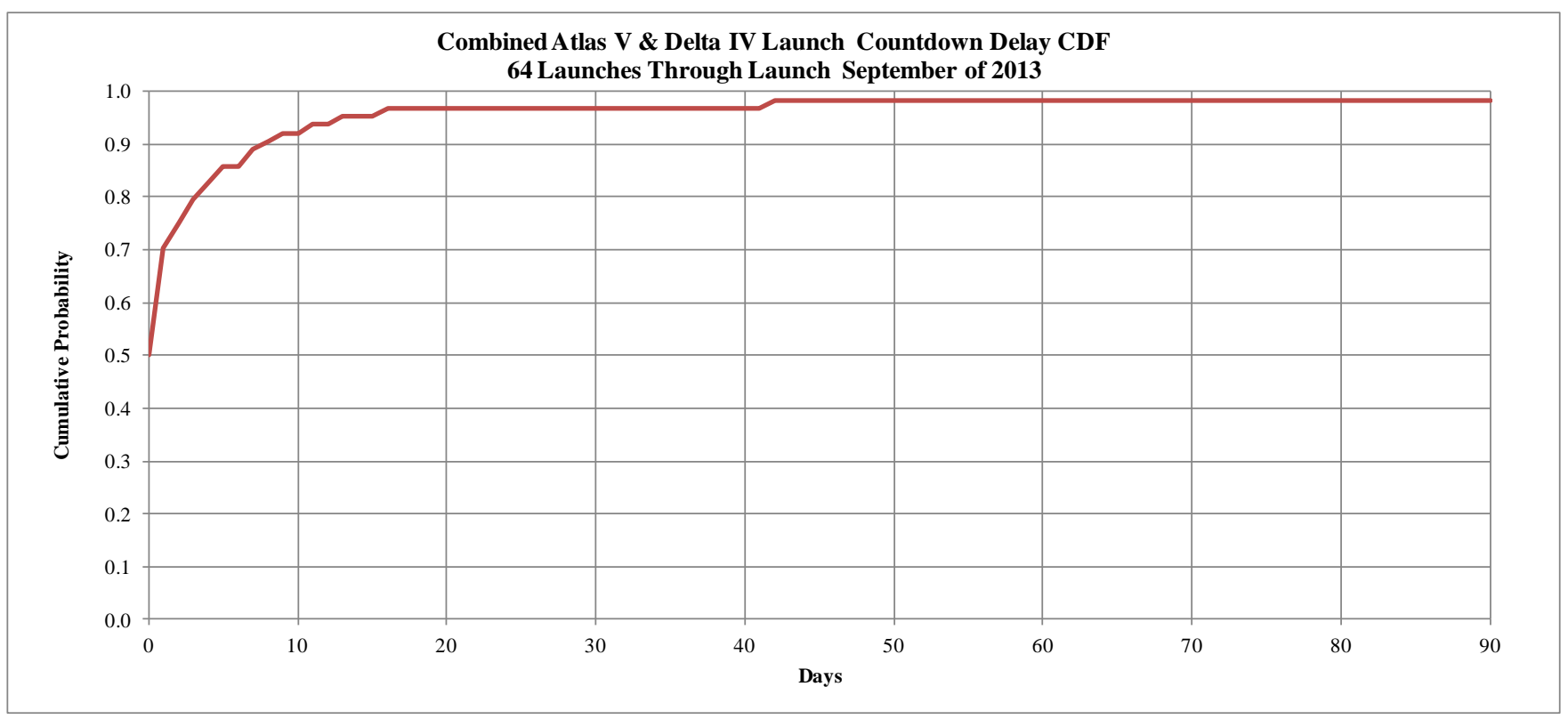

Figure 8 - Non-SLS Launch Countdown Delay Risk Model

Ascent Loss of Mission Risk-The launch and ascent of a vehicle into LEO is typically one of the most risky phases in any space mission. Conducting multiple launches into LEO to support the mission means that the assembly campaign is exposed to this risk multiple times.

The design concept of the $130 \mathrm{t}$ SLS has not been finalized and there is not an official reliability requirement or estimate available at this time. Consequently, the SLS ascent loss of mission risk was estimated by mapping vehicle configuration assumptions to available analog analysis and historical data. The team needed to make assumptions regarding its likely configuration regarding side booster propulsion, numbers of main engines on the core stage, and the configuration of the upper stage. For this analysis cycle, it was assumed that the SLS will have liquid oxygen (LOX)-Kerosene based propellant side boosters with RD-180 class engines, 4 SSME class engines on the core stage, and a LOX-Hydrogen upper stage with $1 \mathrm{~J}-2 \mathrm{X}$ engine.

The Atlas V vehicle with its RD-180 based first stage provides a potential analog for the reliability of the twin liquid boosters of the $130 \mathrm{t}$ SLS. A study by the Futron Corporation places the expected Atlas V (401 variant) failure rate due to propulsion and separation events at 1.78E-2 [13]. However, this value includes Centaur Upper Stage risk. Subtracting out the 1.2E-2 Centaur contribution yields a value of 5.87E-3 for the failure rate of the core stage of the Atlas V. This becomes the analog estimate for the SLS side stage failure rate. Since the SLS has twin side stages, the effective failure rate for the two side stages is 1.17E-2.

The ascent reliability of the SLS core stage is based upon the STS SSME experience of 1 SSME shutdown in 135 missions which yields a value of 0.9975 . The resulting loss of mission risk for an SLS core stage with 4 SSME class engines is $9.840 \mathrm{E}-3$.

The Saturn's upper stage J-2 engine and Centaur upper stage provide useful analogs for estimating upper stage reliability on the $130 \mathrm{t}$ SLS. The projected reliability of the J-2 engine was 0.988 at the beginning of the Apollo program [14, 15]. This equated to a projected failure rate of $1.2 \mathrm{E}-2$. During Apollo 6, a test flight prior to manned flights, 2 engines on the Saturn V's $2^{\text {nd }}$ stage shut down early and the $3^{\text {rd }}$ stage engine failed to restart. The cause was identified and corrective actions were taken. The subsequent Apollo and Skylab flight history for the J-2 consisted of 70 engines being flown with 1 engine shutdown event. This represented an empirical engine failure rate of approximately $1.4 \mathrm{E}-2$. The Centaur upper stage has a similar failure rate of approximately 1.2E-2 [16]. The analysis presented in this paper uses the $1.2 \mathrm{E}-2$ value for the future SLS upper stage.

Combining the side stage risk of $1.17 \mathrm{E}-2$, the core stage engine risk of $9.84 \mathrm{E}-3$, and the upper stage risk of $1.2 \mathrm{E}-2$ yields a combined ascent probability of loss of mission $\left(\mathrm{P}_{\mathrm{LOM}}\right)$ value of 3.317E-2 for the $130 \mathrm{t}$ SLS.

The ascent reliability risk model for the non-SLS launch vehicles is based upon the previously mentioned Futron study that estimated Atlas $\mathrm{V}$ expected failure rate at $1.78 \mathrm{E}-$ 2. 1.78E-2 was used for all non-SLS launches.

Automated Rendezvous \& Docking Risk-Assembly of the MTV will require that multiple independently launched elements be aggregated in space. That will require some form of rendezvous and docking of those elements. Because the crew will likely not be present when most of the assembly events occur, the assembly will involve automated rendezvous and docking (ARD) events. Historically, ARD has proved troublesome for in-space vehicles and a number 
of failures have occurred. Failure in the assembly of the MTVs could result in failure of the overall mission. The Exploration Systems Architecture Study (ESAS) estimated the probability of failure for automated docking at 1 in 97 or 1.03E-2 [17].

The failure probability for crew-assisted rendezvous and docking with the MTV is much lower than that for the automated procedure. The ability of the crew to take over in real time mitigates much of the risk. Additionally, the historical data for Space Shuttle and Soyuz crew docking with the Mir and International Space Station (ISS) indicate a high level of reliability. The ESAS report estimated the docking failure rate at 1 in 230 or $4.35 \mathrm{E}-3$ [17].

A related risk that has not been quantified at this point pertains to the reliability of electrical and fluid connections as well as checkout activities associated with in-space assembly of the fractionated elements. More work in this area is required for future studies.

Element System Failure on Orbit-As elements loiter in LEO or at some other potential MTV assembly point, there is the potential that system failures will occur that result in loss of mission. The cumulative potential for loss of mission increases as the loiter period increases.

Since the MTV elements have not been designed, built or operated yet, it is difficult to develop accurate risk models.
For risk modeling during the on-orbit assembly campaign, it is assumed that each of the 4 major MTV elements (NTR Prop, In-Line Tank, Drop Tank, and Payload Elements) is analogous to an Earth orbiting spacecraft.

The reliability risk model for the major MTV elements is based upon work done by Saleh and Castet in which they analyzed a select portion of Ascend's SpaceTrak database. They performed a statistical analysis of 1,584 spacecraft launched between January 1990 and October 2008 including if and when the spacecraft failed. Using this information they developed a spacecraft reliability model (Equation 1) as a function of time spent on orbit. [18].

$$
\begin{gathered}
R(t)=0.9725 \exp \left[-\left(\frac{t}{14310.1}\right)^{0.3760}\right] \\
+0.0275 \exp \left[-\left(\frac{t}{9.3}\right)^{2.9937}\right]
\end{gathered}
$$

From this equation the team determined the probability that a spacecraft would fail as a function of days spent in orbit. Figure 9 shows the failure probabilities over a one year horizon. As seen in the figure, the initial failure probability is relatively high but drops off sharply during the first month on orbit. After the first month, the failure probability continues to decline but at a gentler rate.

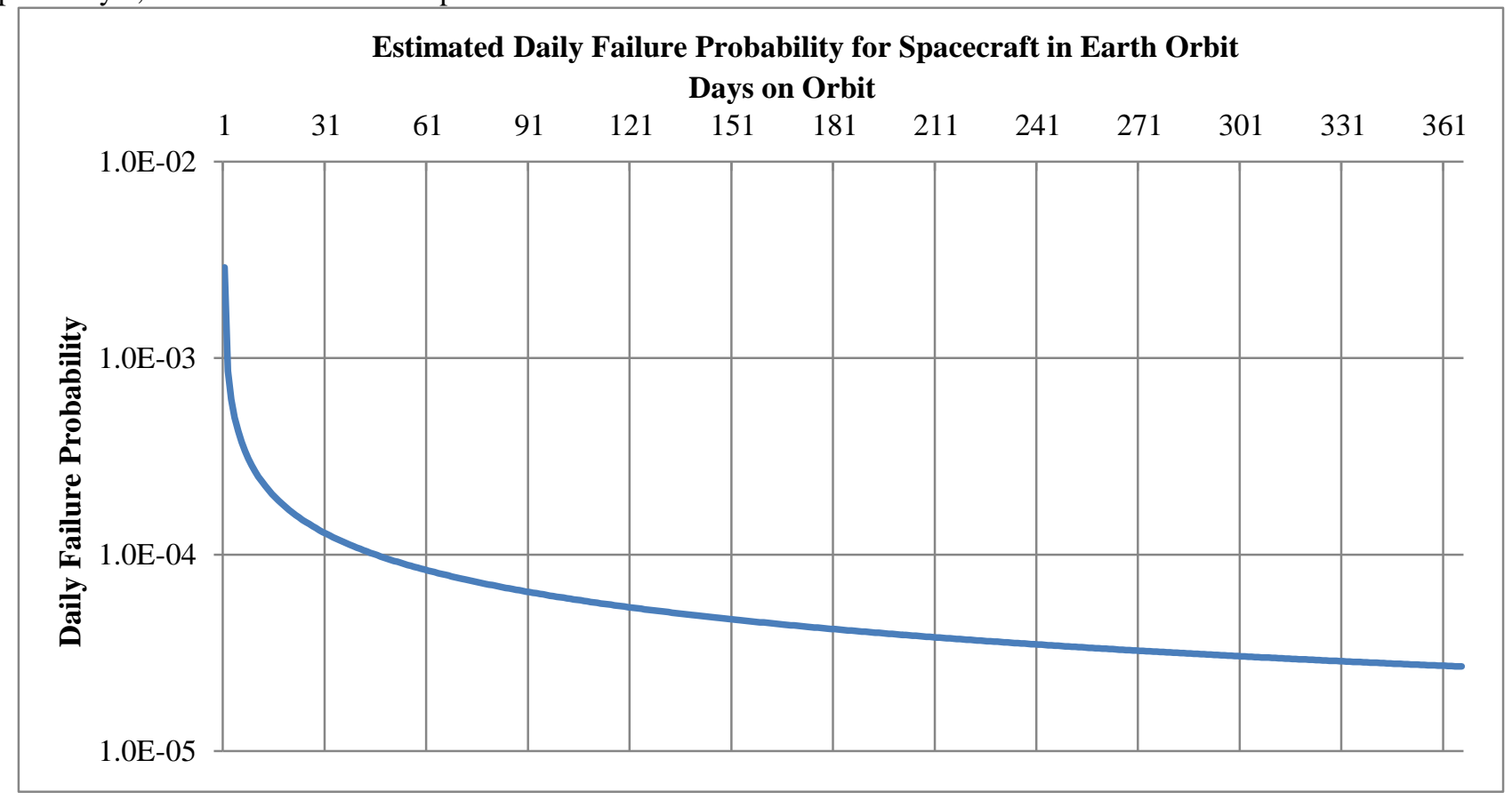

Figure 9 - Spacecraft Failure Probability as a Function of Time on Orbit 
Once established in orbit, an entity representing each major element of the MTV is sent to an element system reliability model where there is a daily chance of an element failure resulting in loss of mission. The daily risks of system failure induced loss of mission for each MTV element continue until the TMI burn. For the SLS-based architecture each SLS launch is assumed to place in orbit one major element. When the major elements are fractionated in order to launch sub-elements on non-SLS launch vehicles, their respective system reliability risk is also fractionated. As an example, the payload elements are considered one spacecraft when launched by the SLS. When the payload elements are fractionated, the HAB is given a factor of 0.6 meaning that it represents $60 \%$ of the payload elements failure risk. The solar array power system and zero boil-off cryo-cooler launched by the Soyuz is given a factor of 0.3 . The docking module and forward RCS prop launched by the HII-B received a factor of 0.1 . The short truss was assumed to have insignificant risk of failure.

MMOD Caused Failures on Orbit-In previous studies, it has been estimated that the per element MMOD risk for elements in LEO is between 5.1E-6 and 5.1E-5 per day. The wide range in values reflects difference in element size and design, particularly in the amount of MMOD protection incorporated in the element, and differences in orbit and orientation. For this study a value of $1.0 \mathrm{E}-5$ per MTV major element per day was used. This represents a somewhat optimistic value, reflecting the assumption that significant MMOD protection would be incorporated into MTV elements.

Crew Medical Risk-Once the crew is launched into Earth orbit and up until the departure burn for Mars, there is the potential that a crew medical event will prompt a decision to return the ailing crew member to Earth. This scenario results in a loss of mission.

Inputs for the crew health risk model are based upon work performed by NASA's Integrated Medical Model (IMM) project team [19]. The IMM is being developed to respond to a significant need identified in NASA's Human Research Roadmap [20] to quantify likelihood and consequence of medical conditions that could occur in spaceflight [21].

Based upon inputs from the IMM community, daily rates of 7.19E-5, 9.72E-5 and 2.05E-4 LOM health events per astronaut-day respectively for optimistic, neutral, and conservative risk settings were previously used in the prior launch and assembly campaign analysis [9]. To reduce the number of simulation runs for this study, the neutral value was assumed for all cases. The planned date for launching the crew relative to the opening of the departure window was also held constant.

Departure Burn Risk - The culmination of the MTV launch and assembly campaign is the TMI burn required to escape Earth orbit. The potential for failure at this point is a function of the reliability of the propulsion system. This is essentially another upper stage burn so the Centaur failure probability value, 1.2E-2 that was previously discussed, was assumed. However, the authors note that this reliability basis of estimate will need to be reconsidered in the future because of differences in the operational concept of the NTR propulsion element and today's upper stages. The NTR element will have been loitering in Earth orbit for an extended duration of time, potentially a year or more. Today's upper stages used to propel spacecraft beyond Earth orbit are typically fired within minutes or hours of launch. Departure burn failures, while resulting in a loss of mission, may still allow the crew to abort back to Earth.

\section{Summary of Risk Factors}

A summary of the post-launch risk factor settings for probability of loss of mission $\left(\mathrm{P}_{\mathrm{LOM}}\right)$ is shown in Table 5 .

Table 5. In-Flight Risk Settings

\begin{tabular}{|l|l|c|}
\hline \multicolumn{2}{|c|}{ Risk Factors } & $\mathrm{P}_{\text {LOM }}$ \\
\hline \multirow{2}{*}{ Ascent } & 130 t SLS & $3.317 \mathrm{E}-02$ \\
\cline { 2 - 3 } & $\begin{array}{l}\text { Non-SLS launch } \\
\text { vehicles }\end{array}$ & $1.780 \mathrm{E}-02$ \\
\hline Rendezvous, \\
$\begin{array}{l}\text { Proximity } \\
\text { Operations \& } \\
\text { Docking/ } \\
\text { Connection } \\
\text { (between MTV } \\
\text { Elements })\end{array}$ & $\begin{array}{l}\text { Crew Directed } \\
\text { (Orion to MTV) }\end{array}$ & $1.030 \mathrm{E}-02$ \\
\hline $\begin{array}{l}\text { MTV Element } \\
\text { reliability (per } \\
\text { Element per } \\
\text { day on orbit) }\end{array}$ & $\begin{array}{l}\text { Continue Saleh and Castet } \\
\text { reliability model (Equation 1) for } \\
\text { subsequent days on orbit }\end{array}$ \\
\hline MMOD (per Element per day on orbit) & $1.000 \mathrm{E}-05$ \\
\hline Health (per person per day on orbit) & 9.720E-05 \\
\hline $\begin{array}{l}\text { Earth orbit departure } \\
\text { burn by NTR propulsion module }\end{array}$ & $1.200 \mathrm{E}-02$ \\
\hline
\end{tabular}

\section{Running the Model}

The simulation ends when either there has been a loss of mission event or the TMI has occurred. 1,000 replications of the simulation are executed to obtain a large data set to analyze. At the end of each replication, the model writes results in an Excel output file. In addition to writing the results to the output file, the deterministic inputs and assumptions that were used during the experiment are also written to the output file.

\section{RESULTS}

The 4-SLS, 3-SLS, and 2-SLS launch and assembly campaign options shown previously in Table 4 were analyzed using the model described. During the analysis cycle the size of the buffers and launch spacing were 
adjusted so as to maximize the reliability of the campaign.

Table 6 shows the optimized campaigns.

Table 6. Optimized Launch and Assembly Campaigns

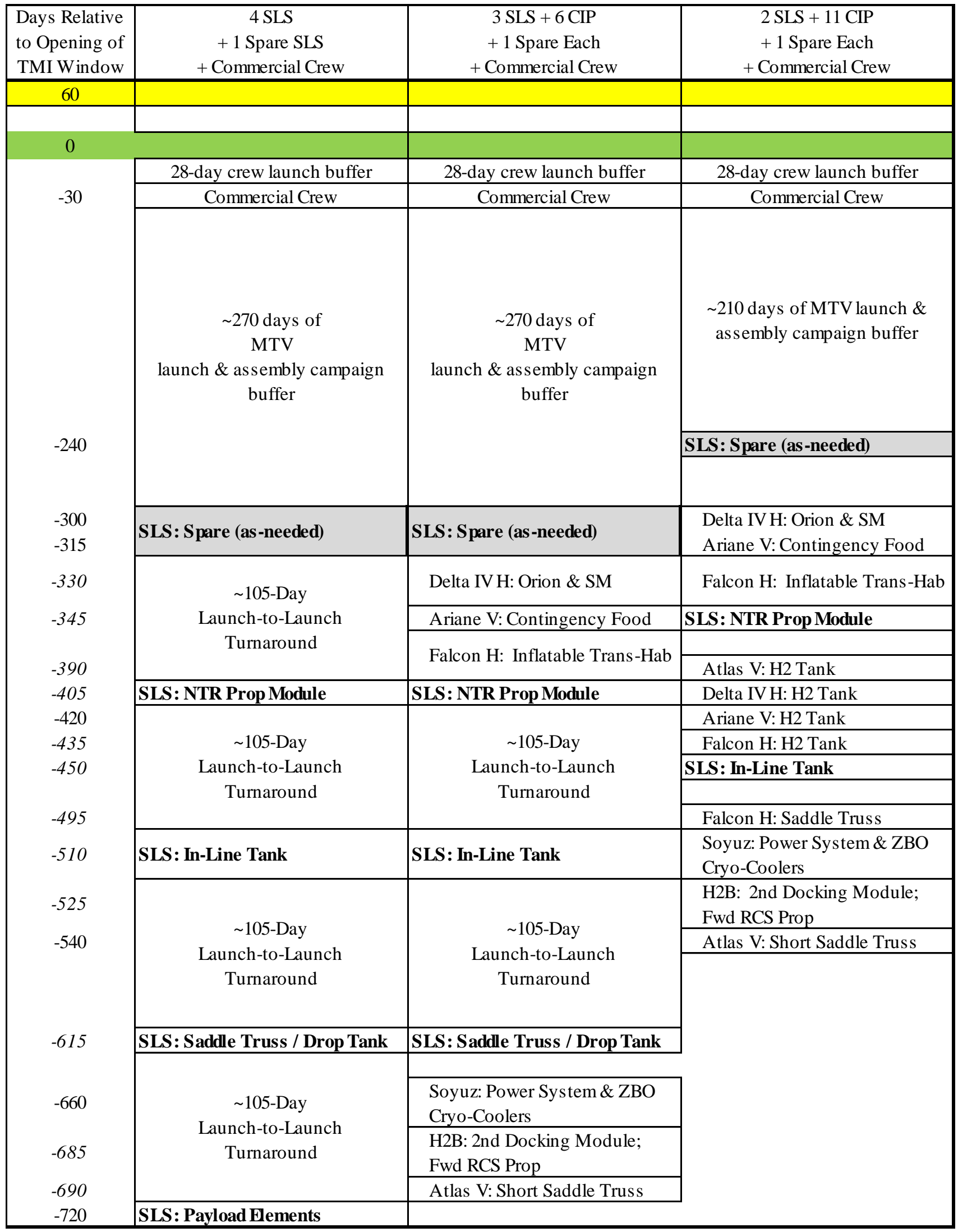


Figure 10 shows the 95 percent confidence interval estimates for the achieved level of reliability for each option. The first thing to note is that the reliability is below 0.90 for all of the options. This means that there is greater than a 10 percent chance that one could lose a significant portion, and potentially all, of the investment made towards a human mission to Mars. The amount of lost investment will depend upon when loss of mission occurs and whether or not launched assets could be salvaged for a future mission. This leads to the question of what level of predicted reliability will be required prior to committing to a multi-billion dollar launch and assembly campaign of international importance? There is, at present, no official reliability requirement for a human mission to Mars, let alone the launch and assembly portion of that mission. The author's judgment is that a value well above 0.90 will be highly desirable.

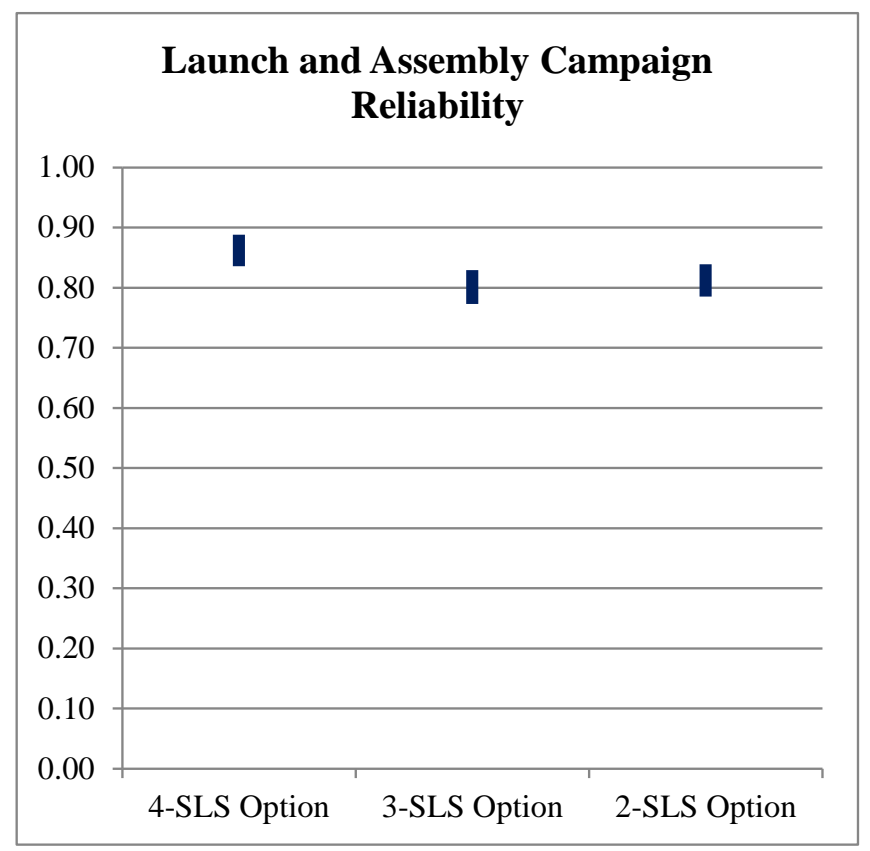

Figure 10 - Campaign Reliability Results

The 4-SLS option has the highest launch and assembly campaign reliability. The 95 percent confidence intervals for the 3-SLS and 2-SLS cases overlap so one cannot identify which is better from these results. However, it is interesting that the 2-SLS case appears to be slightly better. The reduced duration of the 2-SLS case, and the corresponding reduced on-orbit system reliability risk, may account for the differential.

While the 2-SLS and 3-SLS cases are worse than the 4-SLS case in terms of campaign reliability, the difference may be less than one would expect given the large increase in number of launch vehicles. Two factors serve to mitigate the difference. These factors are (1) the ascent reliability difference between the SLS and non-SLS launch vehicles, and (2) the fact that 1 spare was assumed for each launch vehicle type.

\section{CONCLUSIONS AND FORWARD WORK}

A capability to perform integrated launch and assembly campaign reliability risk for international human exploration of Mars has been established. While this paper has focused on the crewed MTV from DRA 5, the capability is extendable to analyze cargo missions as well as other Mars exploration architectures.

An initial finding that may be particularly relevant is that it appears that subdividing some cargo elements of the Mars Transfer Vehicle is possible.

The analytical results indicate that the all-SLS campaign for assembling the Mars Transfer Vehicle is more reliable relative to the mixed launch manifest options. However, the options in which 1 or 2 of the SLS launches are replaced by commercial and international partner launch vehicles are sufficiently reliable to warrant further study. Likewise, considering other options in which additional SLS launches are replaced should be analyzed for comparison as well.

Forward work includes sensitivity analysis to having additional spares and potentially a spare crew launch capability. Having a backup launch to support a crewed launch is not without precedent. For the last Space Shuttle servicing mission to the Hubble Space Telescope, a second Space Shuttle was on an alternate launch pad ready to launch in case the launched mission suffered damage to its thermal protection system such that the crew needed to be rescued [22].

A related sensitivity analysis is to reconsider the model assumptions regarding crew medical risks. For example, what if it was assumed that the mission would not be aborted for an ailing crew member? It is also noteworthy that the assumed risk factor value of 9.72E-5 per crew member per day on orbit (or in space) results in a very high probability of loss of a crew member during the lengthy time from Earth orbit departure to Earth return. Clearly, the crew medical risk for the overall mission will need to be mitigated and this will improve the launch and assembly campaign reliability.

Additional forward work includes updates to risk factors and architecture propulsion assumptions as these have significant influence over the results. The team will also consider additional constraints and capabilities as they emerge from NASA and potentially commercial and international partner programs designing, building and operating the systems that will be required for human exploration of Mars. 


\section{REFERENCES}

[1] Drake, B.G., "Human Exploration of Mars, Design Reference Architecture 5.0" NASA-SP-2009-566, July 2009.

[2] Drake, B.G., "Human Exploration of Mars, Design Reference Architecture 5.0 Addendum" NASA-SP2009-566-ADD, July 2009.

[3] Cates, G.R., Steele, M.J., Mollaghasemi, M., and Rabadi, G., "Modeling the space shuttle," In Proceedings of the 2002 Winter Simulation Conference, ed. E. Yücesan, C.H. Chen, J. L. Snowdon, and J. M. Charnes, 754-762.

[4] Cates, G.R. and Mollaghasemi, M., "Supporting The Vision For Space With Discrete Event Simulation," In Proceedings of the 2005 Winter Simulation Conference, M. E. Kuhl, N. M. Steiger, F. B. Armstrong, and J. A. Joines, eds., 1306-1310.

[5] Cates, G.R., and Mollaghasemi, M., "A Discrete Event Simulation Model For Assembling The International Space Station," In Proceedings of the 2005 Winter Simulation Conference, M. E. Kuhl, N. M. Steiger, F. B. Armstrong, and J. A. Joines, eds., 1260-1264.

[6] Stromgren, C. et al, "Launch Order, Launch Separation and Loiter in the Constellation $11 / 2$ Launch Solution," 2009 IEEE Aerospace Conference, 978-1-4244-2621-8, 2009.

[7] Cates, G.R., et al, "Low earth orbit rendezvous strategy for lunar missions," Proceedings of the IEEE 2006 Winter Simulation Conference, 1-4244-0500-9, 2006.

[8] Cirillo, W.M, et al, "Risk Analysis of On-Orbit Spacecraft Refueling Concepts," AIAA Space 2010 Conference \& Exposition, AIAA-2010-8832, 30 Aug. - 2 Sep. 2010, Anaheim, California.

[9] Cates, G.R., et al, "Launch and Assembly Reliability Analysis for Human Space Exploration Missions," 2012 IEEE Aerospace Conference, 2012.

[10] Cates, G.; et al, "Launch and assembly reliability analysis for Mars human space exploration missions," Aerospace Conference, 2013 IEEE Aerospace Conference, 2013.

[11] Space Explorations Technology website: http://www.spacex.com/

[12] Rockwell Automation's Arena: http://www.arenasimulation.com/

[13] Futron Corporation, "Design Reliability Comparison for SpaceX Falcon Vehicles," November 2004: http://www.spacex.com/FutronDesignReliability.pdf
[14] NASA, Apollo Saturn 504 Mission Reliability Analysis Appendix C, Washington D.C., 1965.

[15] Krevor, Z.C. and Wilhite, A., "Launch Vehicle Engine Selection Using Probabilistic Techniques," $48^{\text {th }}$ AIAA/ASME/ASCE/AHS/ASC Strucgtures, Structureal Dynamics, and Materials Conference, April 23-26, 2007, AIAA 2007-1961.

[16] Smith, K.R. et al, "Cryogenic Upper Stage System Safety," Proceedings of the $1^{\text {st }}$ IAASS Conference, 25-27 Oct. 2005, Nice, France. Also available on NASA Technical Reports Server Document ID 20050242041 http://ntrs.nasa.gov/archive/nasa/casi.ntrs.nasa.gov/20050 242041_2005246348.pdf

[17] NASA, "Exploration Systems Architecture Study," page 598, 2005.

[18] Saleh, J.H. and Castet J-F., Spacecraft Reliability and Multi-State Failures: A Statistical Approach, Wiley, 2011.

[19] Butler, D.J. and Kerstman E., "The Integrated Medical Model," presentation to NASA Human Research Program Investigators' Workshop, 4 Feb. 2010: http://ntrs.nasa.gov/archive/nasa/casi.ntrs.nasa.gov/20100 005626_2010005183.pdf

[20] NASA Human Research Roadmap website: http://humanresearchroadmap.nasa.gov/

[21] NASA Human Research Roadmap Gap ExMC 2.01: http://humanresearchroadmap.nasa.gov/Gaps/?i=384

[22] Hamlin, T.L., Canga, M.A., and Cates, G.R., "Hubble Space Telescope Crew Rescue Analysis," In Proceedings of the 10th International Probabilistic Safety Assessment \& Management Conference, 7-11 June 2010, Seattle Washington. 


\section{BIOGRAPHIES}

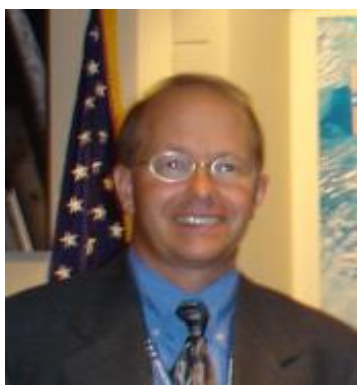

Grant Cates is a Chief Scientist at SAIC. He retired from NASA in 2006 after 25 combined years in federal service, including 7 years on active duty in the Air Force. At NASA he served in varying capacities on the Space Shuttle Program, including Space Shuttle Columbia Vehicle Manager and Flow Director. He received a Ph.D. in Industrial Engineering from the University of Central Florida in 2004.

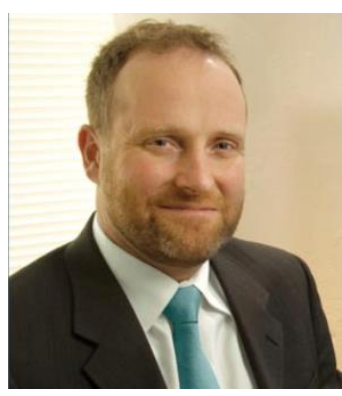

Chel Stromgren currently serves as the Chief Scientist of Binera, Inc. Risk Analytics Division. In this role, $\mathrm{Mr}$. Stromgren leads the development of probability and risk-based strategic models and strategic analysis of complex system development. Mr. Stromgren has supported NASA in the analysis of Space Shuttle and International Space Station operations in the post-Columbia environment and has led the development of strategic campaign models for the lunar exploration initiatives. He holds a Bachelor of Science degree in Marine Engineering and Naval Architecture from the Webb Institute and a Master of Science degree in Systems Management from the Massachusetts Institute of Technology.

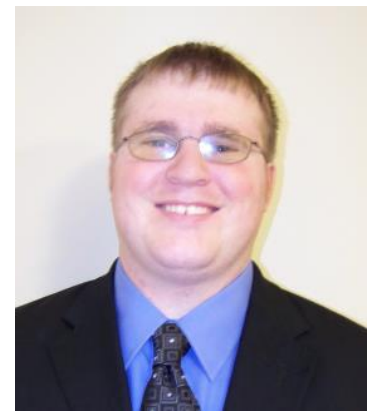

Dr. Dale Arney is an aerospace engineer in the Space Mission Analysis Branch at NASA Langley Research Center with expertise in space system architecting and systems analysis. Before starting at NASA, Dr. Arney was a research engineer at the Georgia Institute of Technology, analyzing mission concepts for lunar, nearEarth asteroid, and Mars exploration missions. Dr. Arney received his Ph.D. in Aerospace Engineering in 2012, M.S. in 2008, and B.S. in 2006, all from Georgia Tech.

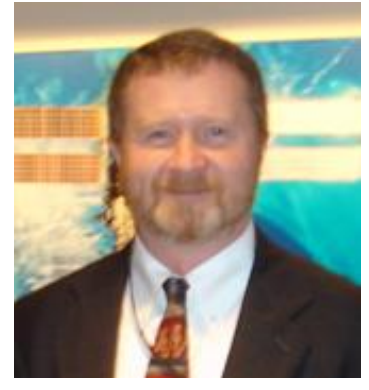

William Cirillo currently serves as a Senior Researcher at NASA Langley Research Center in Hampton, Virginia, where he has worked for the past 20 years in the area of Human Space Flight Systems Analysis. This has included studies of Space Shuttle, International Space Station, and Human Exploration beyond low Earth orbit. In 2005, Mr. Cirillo served at NASA Headquarters as a core member of the Exploration Systems Architecture Study (ESAS) team, where he was responsible for studying the use of Ares I/Orion in meeting future ISS crew and logistics transportation needs. Mr. Cirillo currently leads a team of analysts in assessing at a strategic and tactical level the manifesting of assembly and logistics flights human exploration beyond low Earth orbit.

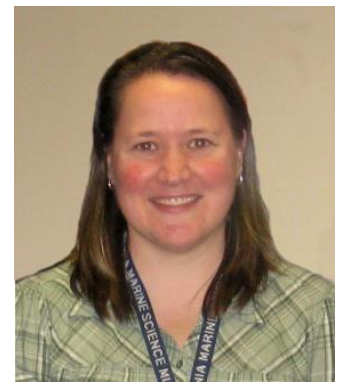

Kandyce Goodliff is an aerospace engineer at NASA Langley Research Center in Hampton, VA, with the Space Mission Analysis Branch (SMAB). Her primary roles as a systems analyst for $S M A B$ are conceptual design and sizing of human and robotic spacecraft, mission and spacecraft analysis, and campaign analysis for human exploration. She has a Bachelor of Science in Aerospace Engineering from Embry-Riddle Aeronautical University and a Master of Science in Mechanical Engineering from the George Washington University.

\section{ACKNOWLEDGEMENTS}

The authors would like to thank David R. Komar (NASA Langley Research Center) for his insight and suggestions on how to fractionate the payloads of the DRA 5.0 missions. 